\title{
Atypical distribution of inflammation in newly diagnosed ulcerative colitis is not rare
}

\author{
Sang Hyoung Park MD¹, Suk-Kyun Yang MD¹, Soo-Kyung Park MD¹, Jong Wook Kim MD², \\ Dong-Hoon Yang $M D^{1}$, Kee Wook Jung $M D^{1}$, Kyung-Jo Kim $M D^{1}$, Byong Duk Ye MD, \\ Jeong-Sik Byeon $M D^{1}$, Seung-Jae Myung $M D^{1}$, Jin-Ho Kim $M^{1}$
}

SH Park, S-K Yang, S-K Park, et al. Atypical distribution of inflammation in newly diagnosed ulcerative colitis is not rare. Can J Gastroenterol Hepatol 2014;28(3):125-130.

BACKGROUND: Appendiceal orifice inflammation (AOI) is a common 'skip lesion' in patients with ulcerative colitis (UC). However, other skip lesions are less well known.

OBJECTIVE: To evaluate the atypical distribution of UC lesions, other than AOI, in terms of their frequency, pattern, risk factors and prognostic implications.

METHODS: A retrospective analysis of colonoscopic findings and clinical course of 240 adult UC patients who were initially diagnosed at Asan Medical Center (Seoul, South Korea) was performed.

RESULTS: Of 240 patients, 46 (19.2\%) showed an atypical distribution of lesions at initial colonoscopy: eight $(3.3 \%)$ had rectal sparing (segmental-type UC); and 38 (15.8\%) had patchy/segmental skip lesions other than AOI. Skip lesions were detected more frequently in proximal segments of the colon than in distal segments $(\mathrm{P}=0.001)$. An atypical distribution was more common in patients with $\mathrm{AOI}(31.3 \%)$ than in those without AOI $(10.6 \% ; \mathrm{P}<0.001)$. The clinical course of patients with an atypical distribution was not different from that of patients with a typical distribution in terms of remission, relapse, disease extension, colectomy and mortality. In addition, of the 36 patients with an atypical distribution of lesions at diagnosis who underwent follow-up colonoscopy, $24(66.7 \%)$ demonstrated a typical distribution of lesions.

CONCLUSIONS: Patchy/segmental skip lesions and rectal sparing occur not infrequently in adult patients with newly diagnosed, untreated UC. As such, these features alone should not be considered to be definitive evidence against a diagnosis of UC. There does not appear to be a prognostic implication of an atypical distribution of lesions.

Key Words: Colonoscopy; Diagnosis; Prognosis; Skip lesion; Ulcerative colitis

U lcerative colitis (UC) is an idiopathic disease characterized by chronic and relapsing inflammation of the colon, and is one of the major conditions belonging to the broad group of inflammatory bowel diseases (IBDs) (1). It is generally accepted that UC always involves the rectum and may progress to involve more proximal portions of the colon in a continuous, nonsegmental fashion (2). However, there are a few exceptions to this general rule. First, endoscopic and histological patchiness and rectal sparing are quite common in treated UC patients (3-5). Second, pediatric, but not adult, patients with new-onset, previously untreated UC often show relative or complete rectal sparing and/or a patchy/segmental involvement of the colon (6-8). Furthermore, absolute or relative rectal sparing is frequently observed (up to $65 \%$ ) in both pediatric and adult patients with UC associated with primary sclerosing cholangitis (9-12). Finally, up to $75 \%$ of patients with distal UC show evidence of periappendiceal
La répartition atypique de l'inflammation n'est pas rare dans les cas de colite ulcéreuse nouvellement diagnostiquée

HISTORIQUE : L'inflammation de l'orifice appendiculaire (IOA) est une lésion discontinue courante chez les patients atteints de colite ulcéreuse (CU). Cependant, il existe d'autres lésions discontinues, qui sont moins connues.

OBJECTIF : Évaluer la fréquence, l'aspect, les facteurs de risque et les conséquences pronostiques de la répartition atypique des lesions de CU autre que l'IOA.

MÉTHODOLOGIE : Les chercheurs ont procédé à une analyse rétrospective des observations coloscopiques et de l'évolution clinique de 240 patients adultes atteints de CU d'abord diagnostiqués au centre médical Asan de Séoul, en Corée du Sud.

RÉSULTATS : Sur 240 patients, 46 (19,2\%) présentaient une répartition atypique des lésions lors de la coloscopie initiale : chez huit d'entre eux (3,3\%), le rectum était épargné (CU de type segmentaire), tandis que $38(15,8 \%)$ avaient des lésions discontinues, irrégulières et segmentaires autres qu'une IOA. Les chercheurs ont décelé plus de lésions discontinues dans les segments proximaux que dans les segments distaux du côlon $(\mathrm{P}=0,001)$. La répartition atypique était plus courante chez les patients ayant une IOA $(31,3 \%)$ que chez ceux sans IOA $(10,6 \%$; $\mathrm{P}<0,001)$. L'évolution clinique des patients dont la répartition était atypique ne différait pas de celle des patients qui présentaient une répartition classique sur le plan de la rémission, des récidives, de la dissémination de la maladie, de la colectomie et de la mortalité. De plus, sur les 36 patients dont la répartition des lésions était atypique au diagnostic et qui ont subi une coloscopie de suivi, 24 (66,7\%) ont présenté une répartition classique des lésions.

CONCLUSIONS : Les lésions discontinues irrégulières et segmentaires et l'épargne du rectum ne sont pas rares chez les patients adultes atteints d'une CU non traitée nouvellement diagnostiqués. Ainsi, ces seules caractéristiques ne devraient pas être considérées comme des raisons catégoriques de réfuter un diagnostic de CU. La répartition atypique des lésions ne semble pas avoir d'effets pronostiques.

inflammation as a 'skip lesion', often referred to as a cecal patch $(13,14)$, appendiceal orifice inflammation $(\mathrm{AOI})(15-17)$ or a periappendiceal red patch (18).

With the increased awareness of these situations and the concomitant advances in endoscopic technologies, studies from Japan identified endoscopic evidence of skip lesions (other than AOI) in newly diagnosed UC patients that manifest as patchy or segmental involvement of the disease in the colon that is discrete from the distal main lesion $(19,20)$. Moreover, 'right-sided' or 'segmental' colitis represent subgroups of UC defined according to extent in Japan (21). However, these lesions sometime lead clinicians to a false diagnosis of other IBDs, such as Crohn disease (CD), because discontinuity of lesions is a characteristic feature in the differential diagnosis of CD and UC (1).

The clinical features and natural course of $U C$ in patients with skip lesions remain unclear. Therefore, we analyzed the endoscopic findings

\footnotetext{
${ }^{1}$ Department of Gastroenterology, University of Ulsan College of Medicine, Asan Medical Center, Seoul; ${ }^{2}$ Division of Gastroenterology, Department of
} Internal Medicine, Inje University Ilsan Paik Hospital, Ilsanseo-gu, Goyang-si, Gyeonggi-do, Korea

Correspondence: Dr Suk-Kyun Yang, Department of Gastroenterology, University of Ulsan College of Medicine, Asan Medical Center, 88 Olympic-ro 43-gil, Songpa-gu, Seoul 138-736, Korea. Telephone 82-2-3010-3901, fax 82-2-476-0824, e-mail sky@amc.seoul.kr

Received for publication September 17, 2013. Accepted September 19, 2013 
and pattern of distribution of lesions in patients with newly diagnosed, untreated UC to determine the clinical implications and to evaluate the risk factors associated with this atypical distribution.

\section{METHODS}

\section{Patients}

Data obtained from the medical and endoscopic records of all patients who were first diagnosed with UC at the Asan Medical Center, a university hospital in Seoul, South Korea, between January 2001 and December 2009 were analyzed retrospectively. UC was definitively diagnosed in those who met all three of the following criteria: a typical history of diarrhea or blood and pus, or both, in the stool for $>4$ weeks; a typical colonoscopic picture showing diffusely granular, friable or ulcerated mucosa; and characteristic histopathological signs of inflammation on biopsy (22-25). In addition, patients with rectal sparing or skip lesions (either patchy or segmental) were included and considered to have an atypical distribution of UC if their main lesions were typical of UC and their skip lesions had the same characteristics as the main lesions, both endoscopically and histologically. Because AOI is a common feature of UC (found in $>50 \%$ of patients in some studies $[13,16,26])$ and requires no further diagnostic workup to exclude CD (as stated in the European consensus [27]), AOI was not considered to be an atypical UC lesion in the present study. Subjects were excluded if they had been prescribed systemic steroids or immunosuppressive agents for any disease at the time of UC diagnosis, or if they did not undergo complete ileocolonoscopy at the time of UC diagnosis. Subjects were also excluded if they had received nonsteroidal antiinflammatory drugs at the time of UC diagnosis. Thirty-four patients from the authors' previous AOI studies $(16,17)$ were also included in the present study.

\section{Methods}

Baseline demographic and clinical features, including sex, age, duration of symptoms, smoking habits, perinuclear antineutrophil cytoplasmic antibody (pANCA) status, extent of disease, endoscopic disease activity and AOI status at the time of UC diagnosis were evaluated. Total colonoscopy, including evaluation of the terminal ileum, was performed in all patients using a video colonoscope (CF-H260AL/CF-240L/CF-230L, Olympus Optical Co, Japan) after bowel preparation using $4 \mathrm{~L}$ of polyethylene glycol-electrolyte lavage solution. Photographs were taken of each segment including the terminal ileum, cecum, ascending colon and onward. Colonoscopic photographs were analyzed by one author (SKY) who was blinded to the clinical course of the patients. The extent of disease was classified as proctitis, left-sided colitis or extensive colitis on the basis of the colonoscopic findings. Proctitis was defined as disease involving up to $15 \mathrm{~cm}$ from the anal verge; left-sided colitis as disease up to the splenic flexure; and extensive colitis as disease beyond the splenic flexure. The term 'pancolitis' was used to indicate extensive colitis involving the entire colon. In addition, segmental-type UC was defined as UC-like inflammatory lesions (of any extent) in the colon without endoscopic evidence of rectal involvement. AOI and other skip lesions were not considered when classifying the extent of disease. Endoscopic disease activity was classified as mild, moderate or severe according to the endoscopy subscore of the Mayo score (28). Mild disease was characterized as erythema, a decreased vascular pattern and mild friability; moderate disease as marked erythema, an absent vascular pattern, friability and erosions; and severe disease as spontaneous bleeding and/or ulceration.

To investigate changes in the atypical distribution of lesions and the extent of the disease over time, follow-up colonoscopy was performed at one- to three-year intervals, with shorter intervals if clinically indicated. Proximal disease extension was defined as the extension, at any follow-up colonoscopy, of macroscopic inflammation beyond the initially involved segment (ie, from proctitis to left-sided or extensive colitis, or from left-sided colitis to extensive colitis). The subsequent clinical features and follow-up colonoscopic findings were analyzed and compared according to the initial atypical distribution of lesions. The study protocol was approved by the Institutional Review Board of the Asan Medical Center.

\section{Statistical analysis}

Database management and statistical analyses were performed using SPSS version 17.0 (IBM Corporation, USA) for Windows (Microsoft Corporation, USA). When appropriate, results were expressed as proportions or medians and compared using the Mann-Whitney $U$ test. The $\chi^{2}$ test or Fisher's exact test were used to compare categorical variables. The cumulative rate of disease relapse was calculated using the Kaplan-Meier method, and the values were compared between groups using the log-rank test; $\mathrm{P}<0.05$ was considered to be statistically significant.

\section{Baseline characteristics}

\section{RESULTS}

During the study period, 2200 patients with UC visited the outpatient clinic of the Asan Medical Center. Of these, 267 (12.1\%) were initially diagnosed with UC at this institution. Twenty-seven patients were excluded: 10 had received systemic steroids or immunosuppressive agents for diseases other than UC; and 17 did not undergo total colonoscopy at diagnosis. The remaining 240 patients were included in the analysis.

Of the 240 patients, $132(55.0 \%)$ were male and 108 (45.0\%) were female, yielding a male-to-female ratio of $1.22: 1$. The median age at diagnosis was 41 years (range 16 to 79 years) and the median interval from onset of symptoms to diagnosis was 5.3 months (range 0 to 369 months). Of the 240 patients, 44 (18.3\%) were current smokers and $87(36.3 \%)$ were pANCA seropositive. At diagnosis, 125 patients $(52.1 \%)$ had proctitis, 51 (21.3\%) had left-sided colitis and $56(23.3 \%)$ had extensive colitis. The remaining eight $(3.3 \%)$ patients had segmental-type UC. Of the 56 patients with extensive colitis, 39 had pancolitis.

Within the total cohort, 99 (41.3\%) patients (54 male and 45 female) were identified as having AOI at diagnosis. If the 39 patients with pancolitis from the total cohort were excluded, AOI was present in $49.3 \%$ of patients ( 99 of 201). Endoscopic disease activity at diagnosis was mild in $101(42.1 \%)$ patients, moderate in $88(36.7 \%)$ and severe in $51(21.3 \%)$.

\section{Atypical distribution of lesions}

Of the 240 patients, $46(19.2 \%)$ showed an atypical distribution of lesions at the initial colonoscopy. Eight (3.3\%) patients had rectal sparing (segmental-type UC), with no evidence of skip lesions; the distribution of the lesions in these eight patients is summarized in Table 1 . The remaining 38 (15.8\%) patients had skip lesions other than AOI: 23 (60.5\%) had patchy skip lesions (Figure 1A); 13 (34.2\%) had segmental skip lesions (Figure 1B); and two (5.3\%) had both patchy and segmental skip lesions. Skip lesions were found in $19(15.2 \%)$ of 125 patients with proctitis, nine $(17.6 \%)$ of 51 with left-sided colitis and $10(17.9 \%)$ of 56 with extensive colitis. Figure 2 shows the location and proportion of lesions in 19 patients with proctitis and skip lesions. Skip lesions were discovered more frequently in the proximal segments of the colon (transverse colon and ascending colon) than at the distal segments (sigmoid colon and descending colon) $(\mathrm{P}=0.001)$ (Figure 2).

Table 2 summarizes the baseline characteristics of patients with typical and atypical UC. There were no statistically significant differences between the two groups in terms of demographic findings such as sex distribution, age at diagnosis, duration of symptoms before diagnosis and smoking status. In addition, there were no differences between the two groups regarding clinical features at diagnosis, including pANCA status, disease activity and disease extent. However, AOI was identified in $68(35.1 \%)$ of the 194 patients with typical UC and in $31(67.4 \%)$ of 46 patients with the atypical distribution $(\mathrm{P}<0.001)$. If the 39 patients with pancolitis were excluded from the calculations, AOI was present in $68(43.9 \%)$ of the 155 patients with typical UC 
TABLE 1

Initial endoscopic findings and follow-up results of eight patients with segmental-type ulcerative colitis

\begin{tabular}{|c|c|c|c|c|c|c|c|c|}
\hline \multirow[b]{3}{*}{ Patient } & \multirow[b]{3}{*}{ Age/sex } & \multicolumn{6}{|c|}{ Initial location of lesions } & \multirow{3}{*}{$\begin{array}{c}\text { Findings on } \\
\text { follow-up colonoscopy }\end{array}$} \\
\hline & & \multirow[b]{2}{*}{ Cecum } & \multicolumn{4}{|c|}{ Colon } & \multirow[b]{2}{*}{ Rectum } & \\
\hline & & & Ascending & Transverse & Descending & Sigmoid & & \\
\hline$\overline{1}$ & $34 /$ male & + & + & & & & & Extensive colitis \\
\hline 2 & 33/female & + & & + & & & & Left-sided colitis* \\
\hline 3 & 42/male & + & & & & + & & Proctitis \\
\hline 4 & $38 /$ male & & + & + & & & & Proctitis \\
\hline 5 & $50 /$ male & & & + & + & + & & Proctitis* \\
\hline 6 & $50 /$ male & & + & & & & & Proctitis* \\
\hline 7 & 44/female & & + & + & + & + & & No follow-up \\
\hline 8 & $71 /$ male & & & + & & & & No follow-up \\
\hline
\end{tabular}

*Initial proximal lesions remained even after the appearance of rectal involvement, thereby resulting in skip lesions
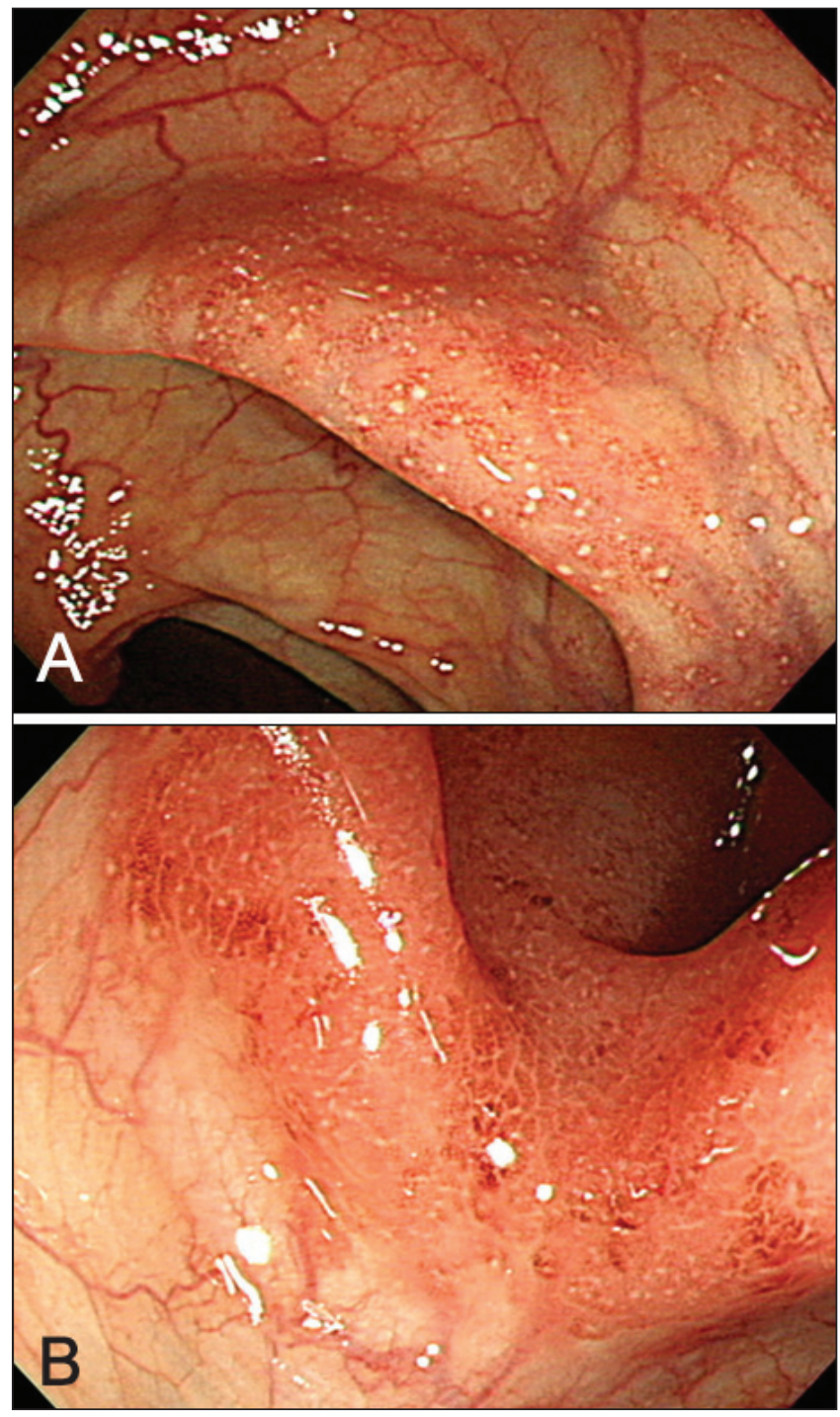

Figure 1) A Patchy skip lesion in the ascending colon. B Segmental skip lesion in the transverse colon

and in $31(67.4 \%)$ of 46 patients with an atypical distribution $(\mathrm{P}=0.007)$. Thus, an atypical distribution was more common in patients with $\mathrm{AOI}(31.3 \%)$ than in those without $\mathrm{AOI}(10.6 \%$; $<<0.001)$.

\section{Clinical course}

The clinical courses of UC according to lesion distribution are summarized in Table 3. The median duration of clinical follow-up was 67 months (range one to 139 months) in the 240 patients. There

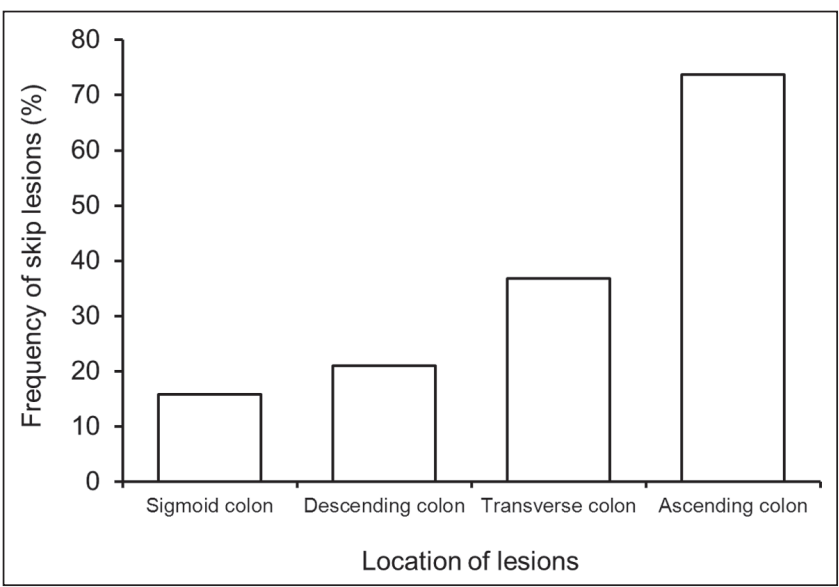

Figure 2) Location of 'skip lesions' in 19 patients with proctitis and skip lesions. Skip lesions were found more frequently in the proximal segments of the colon (transverse colon and ascending colon) than in the distal segments (sigmoid colon and descending colon) $(P=0.001)$

was no difference in the type of treatment during follow-up, the initial remission rate, the cumulative rate of disease relapse, the rate of colectomy or the mortality rate between the two groups.

Follow-up colonoscopic examinations were performed in 160 (66.7\%) of the original cohort of 240 patients (Table 4). The median duration of colonoscopic follow-up was 38 months (range 0.1 to 112 months), with the median number of follow-up colonoscopies being two (range one to seven). There were no differences in baseline characteristics, such as age, sex and endoscopic findings, between patients who were and were not followed-up endoscopically (data not shown). Among the 194 patients with typical UC, 124 (63.9\%) underwent followup colonoscopy, with proximal extension of the disease detected in 21 (16.9\%): from proctitis into left-sided colitis in 12 patients; from proctitis into extensive colitis in four; and from left-sided colitis into extensive colitis in five.

Of the remaining 46 patients with an atypical distribution of lesions (38 with skip lesions, eight with rectal sparing), 36 (78.3\%) underwent follow-up colonoscopy, including 30 with skip lesions and six with rectal sparing. Of these 36 patients, 24 (66.7\%) showed a typical distribution of lesions on follow-up colonoscopy. Proximal extension of the disease occurred in five $(16.7 \%)$ of the 30 patients with skip lesions (excluding the six patients with rectal sparing): from proctitis into left-sided colitis in three patients; and from proctitis into extensive colitis in two patients. The proportion of patients with proximal extension was not different between patients with typical distribution and those with skip lesions $(\mathrm{P}=1.000)$. In the six patients with rectal sparing, there was evidence of rectal involvement at follow-up, with proctitis being detected in four patients, left-sided colitis in one 
TABLE 2

Baseline characteristics of patients with ulcerative colitis according to distribution of lesions

\begin{tabular}{|c|c|c|c|}
\hline & \multicolumn{2}{|c|}{$\begin{array}{l}\text { Distribution } \\
\end{array}$} & \multirow[b]{2}{*}{$\mathbf{P}$} \\
\hline & Typical $(n=194)$ & Atypical $(n=46)$ & \\
\hline Age at diagnosis, years* & $41(17-80)$ & $41(17-71)$ & 0.217 \\
\hline \multicolumn{3}{|l|}{ Sex } & 1.000 \\
\hline Male & $107(55.2)$ & $25(54.3)$ & \\
\hline Female & $87(44.8)$ & $21(45.7)$ & \\
\hline \multicolumn{3}{|l|}{ Smoking } & 0.880 \\
\hline Never smoker & $105(54.1)$ & $26(56.5)$ & \\
\hline Current smoker & $37(19.1)$ & $7(15.2)$ & \\
\hline Ex-smoker & $52(26.8)$ & $13(28.3)$ & \\
\hline $\begin{array}{l}\text { Duration of symptoms } \\
\text { before diagnosis, } \\
\text { months* }\end{array}$ & $4.0(0-123)$ & $5.6(0-369)$ & 0.530 \\
\hline \multicolumn{3}{|l|}{ pANCA } & 0.306 \\
\hline Positive & $67(34.5)$ & $20(43.5)$ & \\
\hline Negative & $127(65.5)$ & $26(56.5)$ & \\
\hline \multicolumn{3}{|l|}{ Initial disease extent } & 0.816 \\
\hline Proctitis & $106(54.6)$ & $19(41.3)$ & \\
\hline Left-sided colitis & $42(21.6)$ & $9(19.6)$ & \\
\hline Extensive colitis & $46(23.7)$ & $10(21.7)$ & \\
\hline Segmental & & $8(17.4)$ & \\
\hline \multicolumn{3}{|c|}{ Initial endoscopic disease activity } & 0.310 \\
\hline Mild & $79(40.7)$ & $22(47.8)$ & \\
\hline Moderate & $70(36.1)$ & $18(39.1)$ & \\
\hline Severe & $45(23.2)$ & $6(13.0)$ & \\
\hline $\mathrm{AOI}$ & $68(35.1)$ & $31(67.4)$ & $<0.001$ \\
\hline
\end{tabular}

Data presented as $n(\%)$. *Data presented as median (range). AOI Appendiceal orifice inflammation; pANCA Perinuclear antineutrophil cytoplasmic antibody

patient and extensive colitis in one patient (Table 1). The median interval from the initial colonoscopy to the identification of rectal involvement was 23.7 months (range 5.8 to 36.6 months) in these six patients. However, initial proximal lesions remained, even after the appearance of rectal involvement, thereby forming skip lesions in three of these six patients. The final diagnosis was not changed to CD in any of the 46 patients who showed an atypical distribution of inflammatory lesions at initial colonoscopy.

\section{DISCUSSION}

To our knowledge, the present study was the first to evaluate the frequency and clinical implications of an atypical distribution of inflammatory lesions other than $\mathrm{AOI}$ in a large number of adult patients with newly diagnosed UC. The initial colonoscopy showed that $19.2 \%$ of patients had rectal sparing $(3.3 \%)$ or skip lesions other than AOI $(15.8 \%)$. This atypical distribution is very high if we consider the classical concept that UC always involves the rectum and may progress proximally in a continuous fashion. We hypothesize that this high rate is due to an increased awareness of skip lesions, such as AOI in UC, as well as improved methods used for bowel preparation and advances in endoscopic technology.
TABLE 3

Clinical course of patients with ulcerative colitis according to distribution of lesions

\begin{tabular}{lccc}
\hline & \multicolumn{2}{c}{ Distribution } & \\
\cline { 2 - 3 } & Typical $(\mathbf{n}=194)$ & Atypical (n=46) & P \\
\hline $\begin{array}{c}\text { Duration of clinical } \\
\text { follow-up, months }\end{array}$ & $66(1-139)$ & $69(2-138)$ & 0.108 \\
Treatment during follow-up & & & \\
5-ASA (topical and/or & $194(100)$ & $46(100)$ & \\
$\quad$ oral) & & & \\
Systemic corticosteroids & $68(35.1)$ & $15(32.6)$ & 0.864 \\
Azathioprine/ & $10(5.2)$ & $5(10.9)$ & 0.173 \\
$\quad$ 6-mercaptopurine & & & \\
Infliximab & $2(1.0)$ & $0(0.0)$ & 1.000 \\
Initial remission rate & $193(99.5)$ & $46(100.0)$ & 1.000 \\
Cumulative rate of disease relapse, $\%$ & & 0.368 \\
1-year relapse rate & 34.8 & 50.5 & \\
3-year relapse rate & 60.2 & 66.1 & \\
$\quad$ 5-year relapse rate & 72.6 & 80.9 & \\
Total proctocolectomy & $2(1.0)$ & $2(4.3)$ & 0.167 \\
Mortality & $3(1.5)$ & $1(2.2)$ & 0.576 \\
\hline
\end{tabular}

Data presented as $n$ (\%) unless otherwise indicated. *Data presented as median (range). 5-ASA 5-aminosalicylic acid

Clinical examiners have a tendency to discontinue a colonoscopic evaluation when they reach the margin between the distal inflamed area and the proximal normal mucosa (29). Additionally, total colonoscopy is not recommended for patients with severely active disease for fear of perforating the colon or exacerbating the colitis (30). However, because we previously performed three studies investigating $\mathrm{AOI}$ in patients with UC (15-17), we routinely examine the entire colon of UC patients for the presence or absence of periappendiceal skip lesions. Moreover, in our previous prospective study (16), we recognized and briefly discussed the presence of skip lesions other than AOI (16). Since then, we have maintained a consensus among our endoscopists to describe all skip lesions, including AOI, which has led to the frequent discovery of other skip lesions in addition to AOI.

Mutinga et al (31) identified patchy, right-sided colonic inflammation in $12(3.4 \%)$ of 352 patients with UC. This figure is much lower than the findings presented in the present study. Also, in contrast to the present study, Mutinga et al included patients with AOI, and nine patients had only microscopic (but not endoscopic) lesions in the right side of the colon. Therefore, the frequency of macroscopic skip lesions other than AOI in the present study is much higher than that reported by Mutinga et al (31). In contrast, retrospective studies from Japan identified skip lesions other than AOI in $23(29.9 \%)$ of 77 patients with newly diagnosed UC (19) and in 20 (45.5\%) of 44 UC patients with AOI (20). Unlike the present study, this Japanese study classified aphthous ulcers at the margin between the distal inflamed area and the proximal normal mucosa as skip lesions, which may account for the higher reported incidence. In addition, if analyzed among the patients with $\mathrm{AOI}$, the frequency of an atypical distribution in the present study would increase to $31.3 \%$ (31 of 99), which makes our findings comparable with those of these other Japanese studies.

\section{TABLE 4}

Follow-up colonoscopic findings according to distribution of lesions

\begin{tabular}{|c|c|c|c|}
\hline & \multirow[b]{2}{*}{ Typical distribution $(n=194)$} & \multicolumn{2}{|c|}{ Atypical distribution $(n=46)$} \\
\hline & & Skip lesion $(n=38)$ & Rectal sparing $(n=8)$ \\
\hline Colonoscopy follow-up & $63.9(124 / 194)$ & $78.9(30 / 38)$ & $75.0(6 / 8)$ \\
\hline Proximal extension of disease & $16.9(21 / 124)$ & $16.7(5 / 30)$ & N/A \\
\hline Change to typical distribution & N/A & $70.0(21 / 30)$ & $50.0(3 / 6)$ \\
\hline
\end{tabular}


The presence of skip lesions contradicts the conventional concept of UC as a strictly continuous disease. Pathologists may prefer the diagnosis of $\mathrm{CD}$ to that of $\mathrm{UC}$ when they encounter skip lesions. However, over a median follow-up of 67 months, none of our patients developed any features consistent with $\mathrm{CD}$ such as ileal lesions, perianal disease or granuloma. In addition, of the 36 patients with an atypical distribution of lesions at diagnosis who underwent follow-up colonoscopy, $24(66.7 \%)$ showed a typical distribution of lesions, which could be due to the disappearance of skip lesions and/or to the appearance of rectal involvement. As such, we are confident that all of our patients with skip lesions or rectal sparing had UC rather than CD.

The results of the present study have important implications with regard to the diagnosis of IBD. Because our results clearly show that patchy or segmental skip lesions and rectal sparing occur not infrequently in adults with newly diagnosed, untreated UC, these features alone should not be considered definitive evidence against a diagnosis of UC. However, what are the prognostic implications of skip lesions or rectal sparing in UC? Rajwal et al (7) suggested that rectal sparing in pediatric patients with UC indicated a more aggressive disease that is less responsive to medical treatment. However, no study has addressed this issue in the adult population. In our previous study, we found no prognostic implications for the presence of AOI skip lesions on the clinical course of UC (16). Similarly, the present study showed that the presence of an atypical distribution of inflammatory lesions in UC patients had no prognostic implications in terms of rates of remission, relapse, disease extension, colectomy and mortality. Instead, we identified a clear correlation between the presence of an atypical distribution and AOI; however, we cannot offer a logical explanation as to the biological meaning of this relationship.

The present study had several limitations. First, it was retrospective in design. Although there was a consensus among our endoscopists to describe all skip lesions, including AOI, throughout the study period, we cannot exclude the possibility that some minor skip lesions were missed. Therefore, the actual frequency of an atypical distribution of lesions may be higher than reported. Second, we did not evaluate the small bowel using small-bowel follow-through or computed tomography/magnetic resonance enterography to exclude $\mathrm{CD}$. However, we did evaluate the terminal ileum in all patients using colonoscopy; no patients had terminal ileal lesions. Third, we did not perform histopathological analysis in the present study; therefore, some of our patients who were classified as having skip lesions may show histological evidence of continuous lesions. However, the extent of UC is usually classified according to endoscopic appearance rather than histological findings, as set out in the Montreal classification (32) and in the European (30) and American guidelines (33).

\section{CONCLUSION}

We showed that an atypical distribution of inflammatory lesions is not a rare finding in patients with newly diagnosed UC. Clinicians and pathologists need to be aware that skip lesions and rectal sparing may occur in untreated patients with UC so as to avoid a misdiagnosis of $\mathrm{CD}$ based on the finding of atypical distribution alone can be avoided. Further prospective, large-scale studies are needed to confirm these observations.

FUNDING: This study was supported by a grant of the Korean Health Technology R\&D Project, Ministry of Health \& Welfare, Republic of Korea (A120176).

DISCLOSURES: Suk-Kyun Yang has received a research grant from Janssen Korea Ltd. None of the other authors have financial disclosures or conflicts of interest to declare.

\section{REFERENCES}

1. Podolsky DK. Inflammatory bowel disease. N Engl J Med 2002;347:417-29.

2. Pera A, Bellando P, Caldera D, et al. Colonoscopy in inflammatory bowel disease. Diagnostic accuracy and proposal of an endoscopic score. Gastroenterology 1987;92:181-5.

3. Kim B, Barnett JL, Kleer CG, Appelman HD. Endoscopic and histological patchiness in treated ulcerative colitis.

Am J Gastroenterol 1999;94:3258-62.

4. Odze R, Antonioli D, Peppercorn M, Goldman H. Effect of topical 5-aminosalicylic acid (5-ASA) therapy on rectal mucosal biopsy morphology in chronic ulcerative colitis. Am J Surg Pathol 1993;17:869-75.

5. Bernstein CN, Shanahan F, Anton PA, Weinstein WM. Patchiness of mucosal inflammation in treated ulcerative colitis: A prospective study. Gastrointest Endosc 1995;42:232-7.

6. Glickman JN, Bousvaros A, Farraye FA, et al. Pediatric patients with untreated ulcerative colitis may present initially with unusual morphologic findings. Am J Surg Pathol 2004;28:190-7.

7. Rajwal SR, Puntis JW, McClean P, et al. Endoscopic rectal sparing in children with untreated ulcerative colitis. J Pediatr Gastroenterol Nutr 2004;38:66-9.

8. Washington K, Greenson JK, Montgomery E, et al. Histopathology of ulcerative colitis in initial rectal biopsy in children.

Am J Surg Pathol 2002;26:1441-9.

9. Faubion WA, Jr., Loftus EV, Sandborn WJ, Freese DK, Perrault J. Pediatric "PSC-IBD": A descriptive report of associated inflammatory bowel disease among pediatric patients with psc. J Pediatr Gastroenterol Nutr 2001;33:296-300.

10. Jorgensen KK, Grzyb K, Lundin KE, et al. Inflammatory bowel disease in patients with primary sclerosing cholangitis: Clinical characterization in liver transplanted and nontransplanted patients. Inflamm Bowel Dis 2012;18:536-45.

11. Loftus EV Jr, Harewood GC, Loftus CG, et al. PSC-IBD: A unique form of inflammatory bowel disease associated with primary sclerosing cholangitis. Gut 2005;54:91-6.

12. Ye BD, Yang SK, Boo SJ, et al. Clinical characteristics of ulcerative colitis associated with primary sclerosing cholangitis in Korea. Inflamm Bowel Dis 2011;17:1901-6.

13. D'Haens G, Geboes K, Peeters M, Baert F, Ectors N, Rutgeerts P. Patchy cecal inflammation associated with distal ulcerative colitis: A prospective endoscopic study. Am J Gastroenterol 1997;92:1275-9.

14. Dendrinos K, Cerda S, Farraye FA. The "cecal patch" in patients with ulcerative colitis. Gastrointest Endosc 2008;68:1006-7.

15. Yang SK, Jung HY, Kang GH, et al. Appendiceal orifice inflammation as a skip lesion in ulcerative colitis: An analysis in relation to medical therapy and disease extent. Gastrointest Endosc 1999;49:743-7.

16. Byeon JS, Yang SK, Myung SJ, et al. Clinical course of distal ulcerative colitis in relation to appendiceal orifice inflammation status. Inflamm Bowel Dis 2005;11:366-71.

17. Park SH, Yang SK, Kim MJ, et al. Long term follow-up of appendiceal and distal right-sided colonic inflammation. Endoscopy 2012;44:95-8.

18. Rubin DT, Rothe JA. The peri-appendiceal red patch in ulcerative colitis: Review of the University of Chicago experience. Dig Dis Sci 2010;55:3495-501.

19. Murano M, Inoue T, Kuramoto T, et al. Endoscopic findings of initial active ulcerative colitis. Stom Intest (Tokyo) 2009;44:1492-504.

20. Tanaka T, Okawa K, Ueda W, et al. Clinical study of ulcerative colitis with skipped lesions at the orifice of the appendix. Stom Intest (Tokyo) 2009;44:1534-40.

21. Hisabe T, Hirai F, Matsui T. Diagnosis of ulcerative colitis. J Jpn Soc Coloproctol 2011;64:807-16.

22. Yang SK, Hong WS, Min YI, et al. Incidence and prevalence of ulcerative colitis in the Songpa-Kangdong District, Seoul, Korea, 1986-1997. J Gastroenterol Hepatol 2000;15:1037-42.

23. Garland CF, Lilienfeld AM, Mendeloff AI, Markowitz JA, Terrell KB, Garland FC. Incidence rates of ulcerative colitis and Crohn's disease in fifteen areas of the United States. Gastroenterology 1981;81:1115-24. 
24. Binder V, Both H, Hansen PK, Hendriksen C, Kreiner S, Torp-Pedersen $\mathrm{K}$. Incidence and prevalence of ulcerative colitis and Crohn's disease in the county of Copenhagen, 1962 to 1978. Gastroenterology 1982;83:563-8.

25. Tysk C, Jarnerot G. Ulcerative proctocolitis in Orebro, Sweden: A retrospective epidemiologic study, 1963-1987. Scand J Gastroenterol 1992;27:945-50.

26. Matsumoto T, Nakamura S, Shimizu M, Iida M. Significance of appendiceal involvement in patients with ulcerative colitis. Gastrointest Endosc 2002;55:180-5.

27. Stange EF, Travis SP, Vermeire S, et al. European evidence-based Consensus on the diagnosis and management of ulcerative colitis: Definitions and diagnosis. J Crohns Colitis 2008;2:1-23.

28. Schroeder KW, Tremaine WJ, Ilstrup DM. Coated oral 5-aminosalicylic acid therapy for mildly to moderately active ulcerative colitis. A randomized study. N Engl J Med 1987;317:1625-9.

29. Okawa K, Aoki T, Sano K, Harihara S, Kitano A, Kuroki T. Ulcerative colitis with skip lesions at the mouth of the appendix: A clinical study. Am J Gastroenterol 1998;93:2405-10.
30. Dignass A, Eliakim R, Magro F, et al. Second European evidencebased consensus on the diagnosis and management of ulcerative colitis Part 1: Definitions and diagnosis. J Crohns Colitis 2012;6:965-90.

31. Mutinga ML, Odze RD, Wang HH, Hornick JL, Farraye FA. The clinical significance of right-sided colonic inflammation in patients with left-sided chronic ulcerative colitis. Inflamm Bowel Dis 2004;10:215-9.

32. Silverberg MS, Satsangi J, Ahmad T, et al. Toward an integrated clinical, molecular and serological classification of inflammatory bowel disease: Report of a Working Party of the 2005 Montreal World Congress of Gastroenterology. Can J Gastroenterol 2005;19 Suppl A:5-36.

33. Kornbluth A, Sachar DB. Ulcerative colitis practice guidelines in adults (update): American College of Gastroenterology, Practice Parameters Committee. Am J Gastroenterol 2004;99:1371-85. 


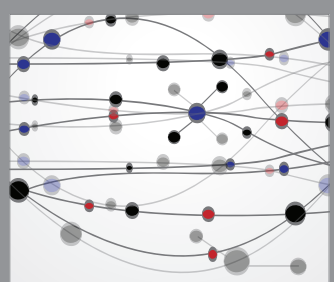

The Scientific World Journal
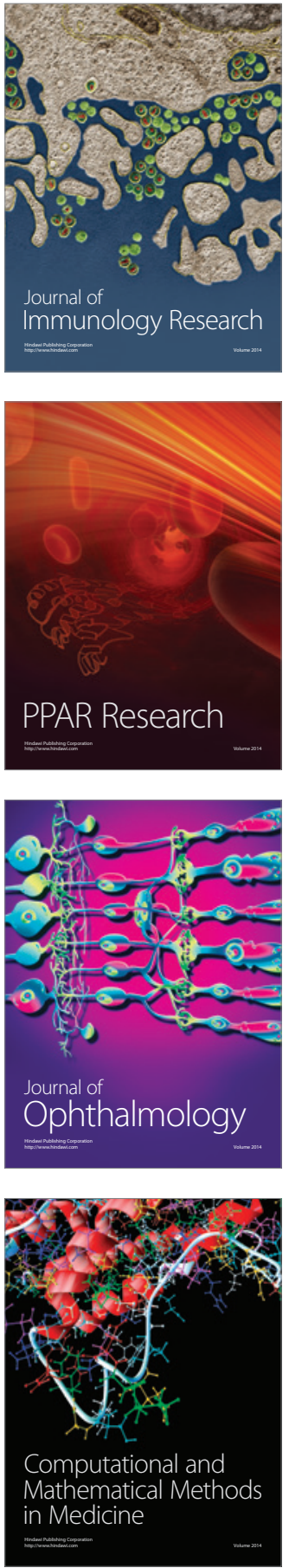

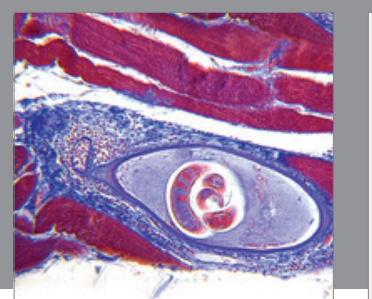

Gastroenterology Research and Practice

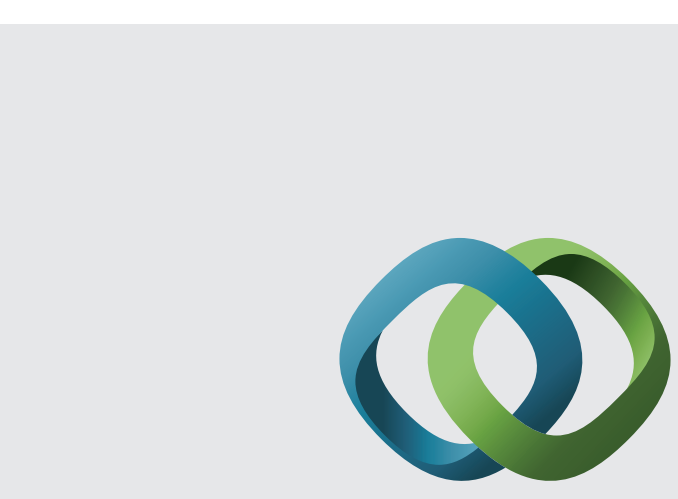

\section{Hindawi}

Submit your manuscripts at

http://www.hindawi.com
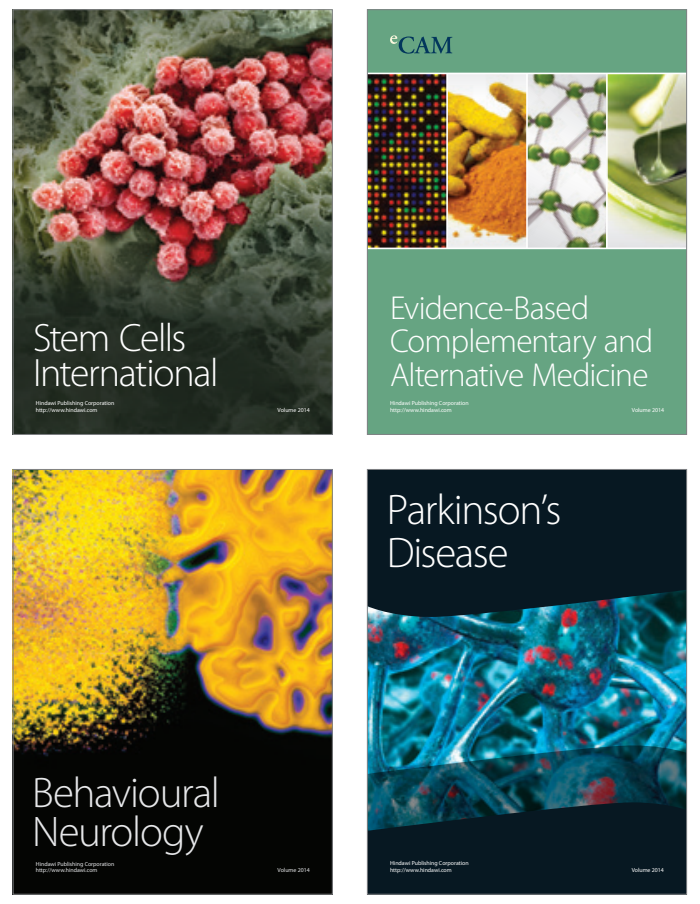
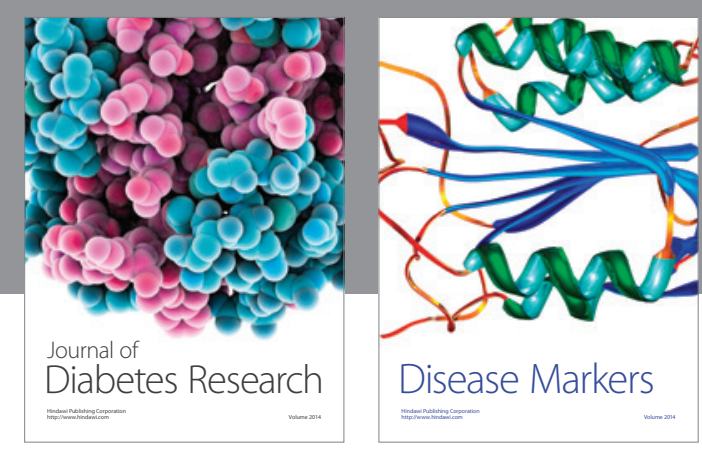

Disease Markers
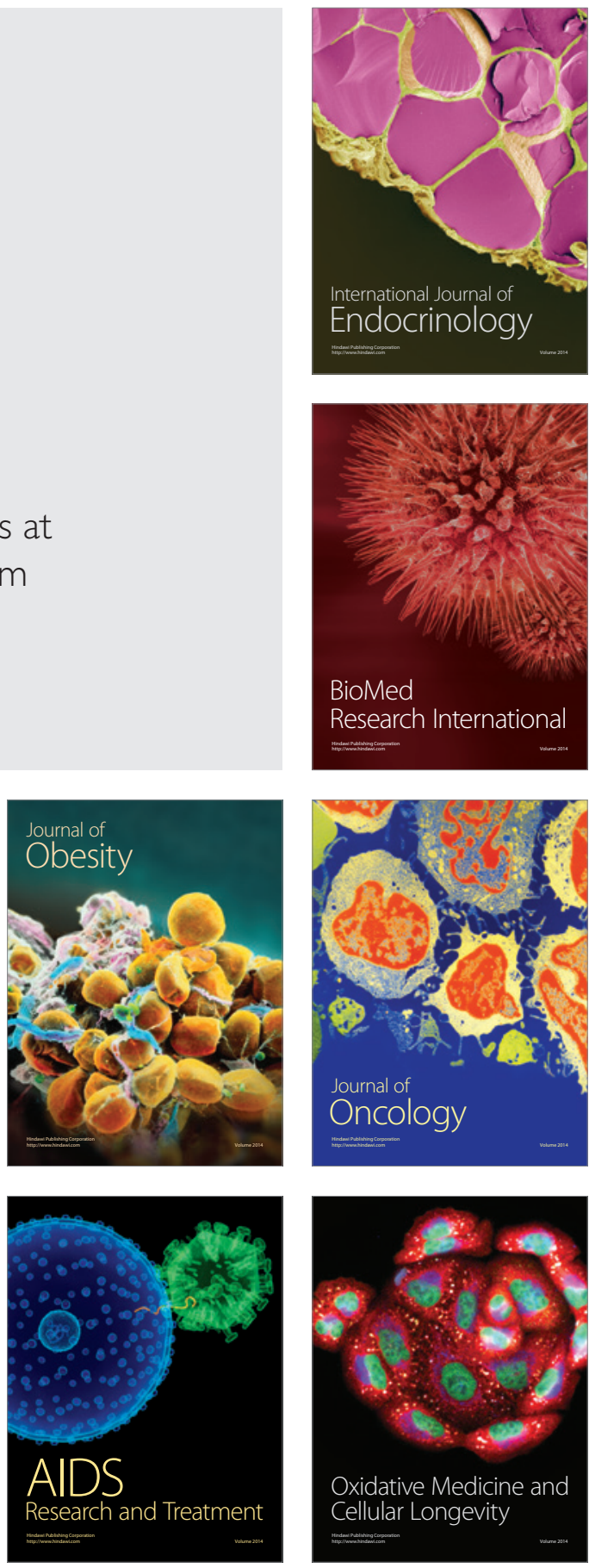